\title{
Human rElafin Inhibits HIV-1 Replication in Its Natural Target Cells
}

\author{
Viraj J. Jasinghe, Erika Arnau Peyrotte, Adrienne F.A. Meyers, Niranjala Gajanayaka, \\ Terry B. Ball, Paul Sandstrom, and Carole Lavigne
}

\begin{abstract}
Trappin-2/elafin is a novel innate immune factor that belongs to the serine protease inhibitor family and has known antibacterial, antifungal, and antiviral properties. In this study, we further investigated the anti-HIV activity of elafin using different cellular models and both X4- and R5-HIV-1 laboratory strains. We compared the antiviral activity of human recombinant elafin (rElafin) with three well-known antiretroviral drugs, AZT, tenofovir, and enfuvirtide. We have found that when the virus is pre-incubated with rElafin prior to the infection of the cells, HIV-1 replication is significantly inhibited. In target T cells and human peripheral blood mononuclear cells, maximal inhibition was achieved using submicromolar concentrations, and rElafin was found to be as potent as enfuvirtide, showing its potential for therapeutic application. We also show data on the mechanism of the antiviral activity of rElafin. We have demonstrated that rElafin neither binds to CD4, CXCR4, or CCR5 host cell receptors, nor to the viral glycoproteins gp120 and gp41. Furthermore, in our cell-to-cell fusion assays, in contrast to enfuvirtide, rElafin failed to block cell fusion. Altogether our results indicate that rElafin interferes with HIV replication at the early steps of its cycle but with a different mechanism of action than enfuvirtide. This study provides the first experimental evidence that elafin inhibits HIV replication in its natural target cells; therefore, elafin might have potential for its development as a new anti-HIV drug or microbicide.
\end{abstract}

Key words: antiviral activity; elafin; HIV; mechanism of action; natural target cells

\section{Introduction}

$\mathbf{E}^{2}$ LAFIN AND ITS PRECURSOR PROTEIN trappin-2 are serine protease inhibitors members of the whey acidic protein (WAP) of the chelonianin family. ${ }^{1-5}$ They are produced by multiple cell types, secreted in mucosal secretions constitutively, and can be elevated in the presence of inflammatory stimuli. ${ }^{1,6-8}$ Trappin-2 possesses an N-terminal transglutaminase substrate-binding domain or cementoin domain and a C-terminal WAP domain that contains four disulfide bonds corresponding to elafin. ${ }^{9,10}$ Elafin, also named skin-derived antileukoprotease, was originally isolated as an elastase inhibitor from the skin of patients with psoriasis, ${ }^{9}$ but is produced by epithelia, particularly in the lung. ${ }^{11,12}$

Trappin-2/elafin has been shown to display anti-inflammatory activity by inhibiting neutrophil serine proteases such as elastase and proteinase $3,,^{9,13-15}$ antibacterial activities, ${ }^{2,3,16,17}$ antifungal activity, ${ }^{18}$ and more recently, antiHIV activity. ${ }^{19-21}$ We recently have identified elafin by tandem mass spectrometry and enzyme-linked immunosorbent assay (ELISA) in the human female reproductive tract and found that elafin was overexpressed in naturally HIVresistant women compared with HIV-uninfected and -infected women, suggesting its possible role for in vivo protection against HIV-1. ${ }^{22,23}$ Ghosh et al. ${ }^{20}$ also found elafin by ELISA to be present in the human female reproductive tract from both HIV-positive and HIV-negative women with a general trend of higher levels in HIV-negative women, while not significant statistically, indicating again that elafin might be an endogenous antiviral molecule. However, in that study, in vitro anti-HIV activity of cervicovaginal lavage (CVL) collected from HIV-positive and HIV-negative women did not correlate with CVL of trappin-2/elafin and SLPI but with MIP3 and HBD2 levels. ${ }^{24}$ By contrast, in a more recent study, elevated levels of trappin-2/elafin identified in CVLs from HIV-1 resistant commercial sex workers were found to be associated with in vitro anti-HIV activity in the genital epithelial cell model TZM-bl. ${ }^{21}$ Therefore, based on these observed disparities, it is still a debatable whether trappin-2/elafin is a novel innate immune factor protecting against HIV-1 infection, and the exact mechanism of the anti-HIV activity of trappin-2/elafin has not yet been

National HIV and Retrovirology Laboratories, National Microbiology Laboratory, Public Health Agency of Canada, Ottawa, Canada. 
characterized. Although it has been suggested that the protective effect of trappin-2/elafin against HIV might be the result of a direct and indirect effect of elafin on HIV, ${ }^{21,24}$ many unknowns still remain and hypotheses and questions raised by these recent findings still need to be elucidated. In this study, we wanted to further characterized the anti-HIV-1 activity of elafin using different cell models including the genital epithelial cells TZM-bl but also HIV natural target cells such as T cells, macrophages, and peripheral blood mononuclear cells (PBMCs). In addition, we further investigated the ability of elafin to bind to either host cellular receptors and viral glycoproteins and its effect on cell surface protein expression. The data presented here confirm that trappin-2/elafin represents a potential candidate microbicide to protect and prevent the transmission of HIV and AIDS.

\section{Materials and Methods}

\section{Materials}

Analytical grade solvents and reagents were purchased from Sigma-Aldrich (Oakville, Canada) unless otherwise specified. Antibodies against CD4 and CXCR4 and antimouse Ig isotypes were purchased from BD Biosciences (Mississauga, Canada). Recombinant elafin (rElafin) and AZT were purchased from Sigma-Aldrich. P24 ELISA kits were purchased from Advance Bioscience Laboratories Inc. (Kensington, MD). T20 (Fuzeon) was obtained from HoffmannLa Roche (Mississauga, Canada).

\section{Cell cultures}

The human epithelial cancer cervical cell line TZM-bl was obtained through the U.S. National Institutes of Health (NIH) AIDS Research and Reference Reagent Program, Division of AIDS, National Institute of Allergy and Infectious Diseases, from Dr. John C. Kappes, Dr. Xiaoyun Wu, and Tranzyme Inc. (Durham, NC). ${ }^{25,26}$ TZM-bl cells are a clone of HeLa cells that express human CD4 and the human chemokine receptors CXCR4 and CCR5. In addition, TZM-bl cells express $\beta$-galactosidase and luciferase under the control of HIV LTR, which is transactivated by the HIV Tat protein in relation to the level of virus replication. The human nonHodgkin's T-cell lymphoma cell line Sup-T1 and monocytic THP-1 cells were purchased from the American Type Culture Collection. HeLa-env-Lai cells were kindly provided by Dr. Olivier Schwartz from the Institut Pasteur, Paris, France. HeLa-env-Lai cells stably express HIV-Lai env genes from $\mathrm{X} 4$ virus and Tat in the cytosol. Cells were maintained in Dulbecco's minimum essential medium (DMEM; TZM-bl and HeLa-env-Lai) or RPMI 1640 (Sup-T1 and THP-1; Invitrogen Canada Inc., Burlington, Canada) supplemented with $10 \%$ heat-inactivated fetal bovine serum (Invitrogen), $50 \mu \mathrm{g}$ / $\mathrm{mL}$ gentamicin (Invitrogen), and $2 \mathrm{mM}$ L-glutamine (SigmaAldrich). In addition, HeLa-env-Lai cells were propagated in the presence of $2 \mu \mathrm{M}$ methotrexate. All cells were cultured in $75-\mathrm{cm}^{2}$ culture flasks at $37^{\circ} \mathrm{C}$ in a humidified atmosphere of $5 \% \mathrm{CO}_{2}$ and were harvested when they reached about $80 \%-$ $85 \%$ confluence using $0.25 \%$ trypsin-EDTA solution diluted in phosphate-buffered solution (PBS). Human PBMCs from normal donors were obtained from SeraCare Life Sciences, Inc. (Milford, MA) and maintained in supplemented RPMI culture medium as already described, with $20 \mu \mathrm{g} / \mathrm{mL}$ recom- binant human interleukin-2 (ZeptoMetrix Corp., Buffalo, NY). Prior to HIV-1 infection assays, PBMCs were stimulated with $1 \mu \mathrm{g} / \mathrm{mL}$ phytohemagglutinin-P (PHA-P; Pharmacia Biotech, GE Life Sciences, Baie d'Urfé, QC, Canada) for $24 \mathrm{~h}$ and THP-1 cells treated with $10 \mathrm{ng} / \mathrm{mL}$ phorbol 12-myristate 13-acetate (PMA) and allowed to differentiate into macrophages for 7 days.

\section{Infectivity and inhibition assays}

To test the anti-HIV activity of elafin against HIV-1, we used two different virus strains, the X4 IIIB and R5 BaL strains, and four different cell models. HIV-1 IIIB viral stocks were prepared by infecting target cells with viral stock solutions, and viruses were collected from supernatants. Viral titration was performed in target cells to calculate the TCID50. Viral preparations were stored at $-80^{\circ} \mathrm{C}$. First, TZM-bl indicator cells were seeded at $6 \times 10^{3}$ cells per well in a 96-well microtiter plate and allowed to adhere overnight in a humidified $\mathrm{CO}_{2}$ incubator at $37^{\circ} \mathrm{C}$. Varying doses of human rElafin or antiretroviral drugs in complete DMEM were incubated with HIV-1 IIIB for $1 \mathrm{~h}$ at $37^{\circ} \mathrm{C}$ in a final volume of $1 \mathrm{~mL}$. Following incubation, the culture medium was aspirated from TZM-bl cells, and $100 \mu \mathrm{L}$ of the mixture containing the virus at multiplicity of infection (MOI) 0.1 was added to the cells. Cells were then incubated for $24 \mathrm{~h}$ at $37^{\circ} \mathrm{C}$ with $5 \% \mathrm{CO}_{2}$ in a humidified incubator. After $24 \mathrm{~h}, \beta$ galactosidase activity was measured using the Beta-Glo assay (Promega, Madison, WI). Briefly, $100 \mu \mathrm{L}$ of Beta-Glo reagent was added to each well, plates were incubated for $30 \mathrm{~min}$ at room temperature, and the light intensity of each well was measured using a luminometer (BioTek Synergy ${ }^{\mathrm{TM}} 2$ instrument, Thermo Fisher Scientific, Nepean, ON, Canada). Uninfected cells were used to determine background luminescence. A subset of experiments were performed to determine possible post-infection inhibitory effects of elafin. In those experiments, TZM-bl cells were first infected with HIV-1 IIIB at MOI 0.1 for $1 \mathrm{~h}$ and then were rinsed with PBS to eliminate unbound viruses. Cells were then incubated with various concentrations of human rElafin or antiretroviral drugs for $24 \mathrm{~h}$ at $37^{\circ} \mathrm{C}$ with $5 \% \mathrm{CO}_{2}$ in a humidified incubator. HIV-1 replication was measured by the Beta-Glo assay. Experiments were repeated three times with four replicates.

Other experiments were conducted using the Sup-T1 T cell line and PBMCs. Varying doses of rElafin or antiretroviral drugs in complete RPMI were incubated with HIV-1 IIIB for $1 \mathrm{~h}$ at $37^{\circ} \mathrm{C}$ in a final volume of $1 \mathrm{~mL}$. After incubation, HIV1 infection of Sup-T1 cells or PBMCs were carried out by incubating $2 \times 10^{5}$ cells with the mixture containing HIV-1 IIIB at MOI 0.1 , for $2 \mathrm{~h}$ at $37^{\circ} \mathrm{C}$ in a humidified atmosphere of $5 \%$ $\mathrm{CO}_{2}$ in a total volume of $1 \mathrm{~mL}$. After infection, cells were washed and plated in 96-well plates, at a density of $2 \times 10^{4}$ cells / well in $100 \mu \mathrm{L}$ of complete RPMI without further addition of rElafin or drugs. At day 4, cells were split and drugfree fresh culture medium was added to the wells. At day 7 , the supernatants were collected and the level of HIV-1 replication was determined by measuring the concentration of viral protein p24 (ELISA assay kit, Advance Bioscience Laboratories Inc.). Syncytium formation and cell viability were also analyzed 7 days post-infection in Sup-T1 experiments by microscopic observations and the MTT assay, respectively. 
THP-1 cells were plated at $4 \times 10^{4}$ cells/well in 96-well plates and treated with $10 \mathrm{ng} / \mathrm{mL}$ PMA to allow them to differentiate. After 7 days of differentiation, PMA-treated cells were exposed to a mixture of HIV-1 BaL pre-incubated with rElafin or antiretroviral drugs for $1 \mathrm{~h}$ at $37^{\circ} \mathrm{C}$ in a humidified atmosphere of $5 \% \mathrm{CO}_{2}$, at a MOI of 0.1 . After $2 \mathrm{~h}$, cells were rinsed and cultured in complete culture medium without further addition of rElafin or drugs. Every 3-4 days, supernatants were collected and drug-free fresh culture medium was added to the wells. HIV-1 replication was monitored by the viral p24 protein level in harvested supernatants. Additional experiments were conducted to determine the $50 \%$ inhibitory concentration $\left(\mathrm{IC}_{50}\right)$ of rElafin or antiretroviral drugs in the different cell models. $\mathrm{IC}_{50}$ was calculated using regression analysis.

Each experimental condition consisted of quadruplicate samples and assays were repeated three times with Sup-T1 cells or twice with PBMCs and THP-1. In all experiments, untreated cells infected with HIV-1 virus only (positive control) and untreated or uninfected cells (negative control) were used.

\section{Cytotoxicity assay}

Sup-T1 cell viability was determined by the MTT assay. Cells were plated and treated as in the infectivity assays except that at day 4 when the cells were split, fresh culture medium containing rElafin or T20 was added. After 7 days of incubation with varying concentrations of rElafin or $1 \mu \mathrm{M}$ T20, $50 \mu \mathrm{L}$ of cell suspension was transferred to another 96-well plate. Then $8 \mu \mathrm{L}$ of a solution of $4 \mathrm{mg} / \mathrm{mL}$ MTT was added to each well, and cells were incubated at $37^{\circ} \mathrm{C}$ in a humidified atmosphere of $5 \% \mathrm{CO}_{2}$ for $2 \mathrm{~h}$. Cells were lysed using isopropanol containing $1 \% \mathrm{HCl} 12 \mathrm{~N}$ and $5 \%$ Triton $\mathrm{X}-100$ and absorbance was measured at $570 \mathrm{~nm}$ on a microplate spectrophotometer reader (BioTek Synergy MX instrument, Fisher Scientific). Experiments were repeated twice with four replicates each.

\section{Analysis of expression of cell surface proteins by flow cytometry}

Effect of rElafin on cell surface protein expression was evaluated using two different cell models, Sup-T1 and TZM-bl expressing CD4 and CXCR4 receptors. Sup-T1 and TZM-bl cells were plated in six-well plates at a density of $1.5 \times 10^{6}$ cells/well in RPMI and DMEM, respectively, supplemented with $3 \%$ serum. Various concentrations of rElafin was added to the cells and at indicated times of incubation, cells were collected, washed, and stained with mouse antihuman monoclonal antibodies (BD Biosciences) for the cellsurface markers CD4 (allophycocyanin [APC], \#340443), CXCR4-PE (phycoerythrin [PE], \#555974), or goat antimouse Ig isotype controls (PE \# 554680, APC \#555576), for $60 \mathrm{~min}$ at $4^{\circ} \mathrm{C}$ in the dark. Cells were then washed again, resuspended in staining buffer $(0.1 \%$ sodium azide and $1 \%$ fetal bovine serum in PBS, pH 7.4-7.6) and fixed with a solution of $2 \%$ formaldehyde in PBS. Cells were analyzed the same day using a FACS Canto II (Becton Dickinson, Franklin Lakes, NJ) and Diva software (Becton Dickinson Biosciences, Mississauga, Canada). Experiments were performed in duplicate and repeated at least twice. Data are expressed in terms of percentage of expression of cell surface markers compared to untreated control cells set at $100 \%$.

\section{Binding of rElafin to cell surface proteins}

Binding of rElafin to cell surface receptors was evaluated using CD4+/CXCR4+ Sup-T1 cell line, whereas binding to viral glycoproteins gp120 and gp41 was evaluated using HeLa-env-Lai cells that stably express HIV-Lai env genes from $\mathrm{X} 4$ virus. Cells $\left(1 \times 10^{6}\right)$ were incubated with indicated concentrations of rElafin for $1 \mathrm{~h}$ at $37^{\circ} \mathrm{C}$ in a total volume of $1 \mathrm{~mL}$ of RPMI or DMEM without serum or antibiotics. After two washes in cold PBS, bound rElafin was detected by incubating the cells with the rat anti-human Trappin-2/Elafin monoclonal antibody (1:10 dilution, R\&D \# MAB1747, clone 257729; R\&D Systems, Minneapolis, MN) for $30 \mathrm{~min}$ at $37^{\circ} \mathrm{C}$ in the dark followed by the chicken polyclonal secondary antibody to rat IgG-FITC (1:100 dilution, Abcam, Toronto, Canada) for $30 \mathrm{~min}$ at $37^{\circ} \mathrm{C}$ in the dark. Binding of rElafin to CD4+/CXCR4 + cells was evaluated by flow cytometry (FACS Canto II) on $5 \times 10^{4}$ events, gated by forward and side scatter and analyzed using Diva software. Level of CD4 and CXCR4 expression using mouse anti-CD4-APC and -CXCR4-PE antibodies (BD Biosciences) was also evaluated in separate samples. Irrelevant human IgG (isotypes control) and cells incubated only with the secondary antibody chicken anti-rat IgG-FITC were used as controls. Data are presented as rElafin bound cells, and the percentage of total gated cells to which nonspecific background evaluated with the control IgG was deduced. Experiments were performed in duplicate and repeated at least twice.

\section{Cell-to-cell fusion assay}

HeLa-env-Lai cells that express HIV-1 envelope glycoproteins gp120 and gp41 on its surface and TZM-bl expressing CD4 and co-receptors CXCR4 and CCR5 were used to assess the effect of rElafin on HIV fusion with cell membrane. When fusion occurs, Tat present in the cytosol of HeLaenv-Lai cells transactivates the long terminal repeat-driven lacZ gene in TZM-bl cells resulting in $\beta$-galactosidase production. HeLa-env-Lai cells were seeded in 48-well plates at a density of $10^{5}$ cells/well in the presence of drugs or water for untreated control wells. One hour later, target cells TZM-bl were added to the wells at the same cell density $\left(10^{5} /\right.$ well) and co-cultured for $24 \mathrm{~h}$ at $37^{\circ} \mathrm{C}$ in a humidified atmosphere of $5 \% \mathrm{CO}_{2}$. The extent of fusion was monitored either by quantification of $\beta$-galactosidase activity in cell lysates (Beta-Glo Assay System, Promega, Madison, WI) as described above or qualitatively by cytochemical staining of cells for $\beta$-galactosidase activity (MAGI-CCR5 Assay, NIH AIDS Research \& Reference Reagent Program), according to the manufacturer's instructions. Briefly, for cytochemical staining, cells were fixed by adding $1 \mathrm{~mL}$ of fixing solution ( $1 \%$ formaldehyde, $0.2 \%$ glutaraldehyde in PBS) to the well for $5 \mathrm{~min}$. Then cells were washed twice with PBS and $200 \mu \mathrm{L}$ of staining solution was added to each well ( $0.2 \mathrm{M}$ potassium ferrocyanide, $0.2 \mathrm{M}$ potassium ferricyanide, $2 \mathrm{M}$

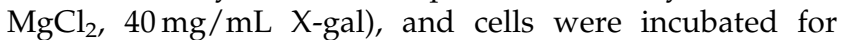
$50 \mathrm{~min}$ at $37^{\circ} \mathrm{C}$ in a non- $\mathrm{CO}_{2}$ incubator. Then cells were washed twice thoroughly with PBS and then analyzed using a Zeiss epifluorescence microscope (Axioscop 40; 


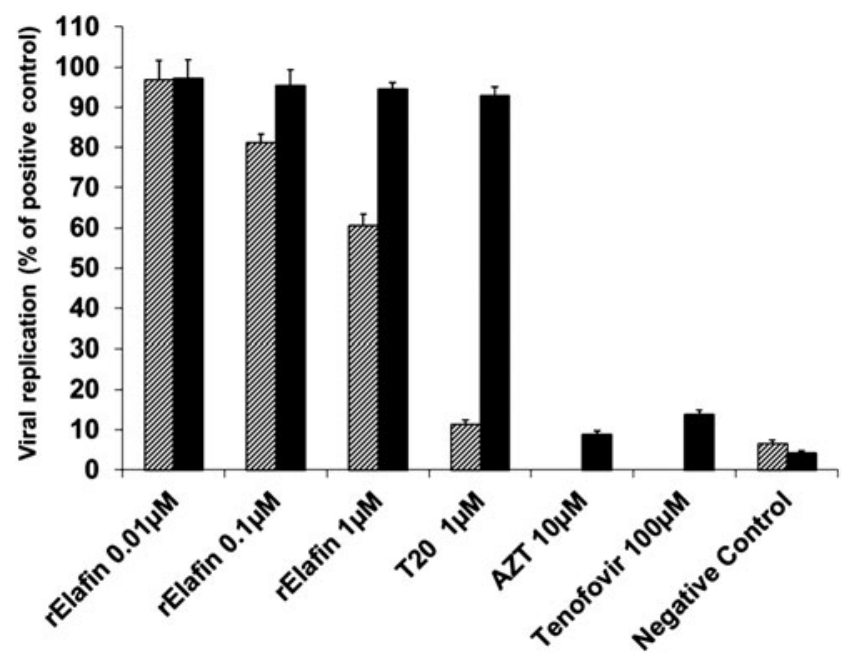

FIG. 1. Anti-HIV-1 IIIB activity of recombinant elafin (rElafin) in TZM-bl cells. TZM-bl cells were infected with HIV-1 IIIB at multiplicity of infection (MOI) 0.1 for $2 \mathrm{~h}$. HIV-1 virus was pre-incubated with rElafin or antiretroviral drugs for one hour before infecting TZM-bl cells (hatched box) or the antiretroviral drugs were added to the cells after infection (black box). Activity of $\beta$-galactosidase released by HIV infection of the cells was quantified by the Beta-Glo assay $24 \mathrm{~h}$ post-infection. Data are expressed in percentages compared with untreated/HIV-infected positive control cells which were set to $100 \%$. Data are representative of three independent experiments. Values represent means of percentage $\pm \operatorname{SEM}(n=4)$.

Carl Zeiss AG, Oberkochen, Germany) and Vision software. Images of light microscopy were taken by a Zeiss camera (AxioCam MRC5, Zeiss, Toronto, Canada).

\section{Statistics}

Statistical analysis of differences between treatment groups was evaluated by Student's $t$ test for unpaired observations using the ANALYSIS TOOLPAK of Microsoft Excel (Redmond, WA) or using ANOVA analysis (SigmaPlot 11.0 software, Systat Software Inc., Chilcago, IL), and $p<0.05$ was considered significant.

\section{Results}

\section{Inhibition of HIV infection in TZM-bl indicator cells}

Inhibitory effects of human rElafin on viral infection was first determined by measuring the virus-induced $\beta$-galactosidase activity in HIV-1 IIIB-infected TZM-bl indicator cells and compared to potent clinically approved antiretroviral drugs (Fig. 1). When the virus was first pre-incubated with rElafin prior to infection of the cells, a concentrationdependent inhibition of HIV-1 replication was obtained, whereas no inhibition was observed when rElafin was added after viral infection. Same data were obtained when cells were treated with the antiretroviral drug T20 known to block HIV entry. In contrast, as expected, reverse transcriptase inhibitors tenofovir and AZT showed high levels of inhibition in the post-incubation experiments when the drugs were added $2 \mathrm{~h}$ after viral infection (Fig. 1). No significant cytotoxicity effect was observed with rElafin or any of the drugs at the doses
TAble 1. Inhibitory Activity of RElafin in Different Cell Models

\begin{tabular}{llc}
\hline Cells & Virus strain & $I C_{50}(n M)$ \\
\hline TZM-bl & HIV-IIIB & $713 \pm 264$ \\
SupT-1 & HIV-IIIB & $79 \pm 7$ \\
PBMC & HIV-IIIB & $176 \pm 7$ \\
THP-1 & HIV-BaL & $89 \pm 2$ \\
\hline
\end{tabular}

Cells were exposed to various concentrations of rElafin, and $\beta$-galactosidase activity (TZM-bl) or p24 protein level (SupT-1, PBMC, and THP-1) was determined, as described in Materials and Methods. The $50 \%$ inhibitory concentration $\left(\mathrm{IC}_{50}\right)$ was determined in the different cell models using regression analysis. Experiments were repeated three times.

used (data not shown). When compared to the infected but untreated TZM-bl control cells, rElafin was found to be 10 -fold less potent than AZT (50\% inhibitory concentration $\mathrm{IC}_{50}$ of $0.71 \mu \mathrm{M}$ compared to $7.13 \mu \mathrm{M}$, respectively), 2-fold less potent than tenofovir $\left(\mathrm{IC}_{50} 1.46 \mu \mathrm{M}\right)$, and similarly potent as $\mathrm{T} 20\left(\mathrm{IC}_{50}\right.$ $0.67 \mu \mathrm{M})$ to reduce $\beta$-galactosidase activity (Table 1 ). Our results in this HeLa cell model suggest that rElafin interferes at early steps of HIV-1 replication with comparable potency as the antiretroviral drugs evaluated since rElafin was able to affect viral replication only when viruses were still at the beginning of the infection cycle (not yet entered into host cells).

\section{Inhibition of HIV infection in Sup-T1 cells}

To further investigate the inhibitory effects of rElafin, we evaluated its potential to inhibit HIV-1 IIIB replication in target $\mathrm{T}$ cells, using Sup-T1 T cell line. The virus was first preincubated for $1 \mathrm{~h}$ with rElafin prior to infection, and then cells were infected with the mixture. After $2 \mathrm{~h}$, the virus mixture was removed and fresh culture medium without drugs was added. Viral replication was quantified by measuring p24 protein production in supernatants after 7 days of infection. In target T cells, rElafin blocked HIV-1 replication in a concentrationdependent manner (Fig. 2A) and showed potent anti-HIV activity with an $\mathrm{IC}_{50}$ of $79 \mathrm{nM}$ (Table 1 ). In uninfected and untreated cells (negative controls), p24 level was $2.62 \pm 1.12 \mathrm{ng} /$ $\mathrm{mL}$ compared with $5022.12 \pm 365.69 \mathrm{ng} / \mathrm{mL}$ in infected and untreated cells (positive controls). As in the previous experiments with TZM-bl indicator cells, rElafin showed lower inhibitory effects when added to the cells $2 \mathrm{~h}$ after infection ( $\mathrm{IC}_{50}$ of $3.32 \mu \mathrm{M}$ in Sup-T1 cells; data not shown). All cell cultures treated with rElafin or T20 were found significantly different from the untreated/infected positive control cells by one-way ANOVA analysis $(p<0.01)$. No significant cytotoxicity effect of rElafin was observed in Sup-T1 cells up to $6.67 \mu \mathrm{M}$ (Fig. 2B).

HIV-1 infection of CD4+ human T-cell lines in culture leads to cytopathic effects characterized by formation of large, multinucleated giant cells called syncytia, followed by destruction and lysis of single cells. The efficacy of rElafin to protect the cells from the lytic effect of HIV-1 was evaluated in Sup-T1 cells infected with the syncytia-inducing X4 tropic HIV-1 IIIB virus using the MTT cell viability assay (Fig. 2C). The lytic effect of HIV-1 was significantly reduced in cells treated with rElafin in a dose-dependent manner in comparison to untreated/infected control cells. At such a low dose as $40 \mathrm{nM}$, rElafin was able to protect viability of Sup-T1 cells at $70 \%$ compared to untreated/uninfected 

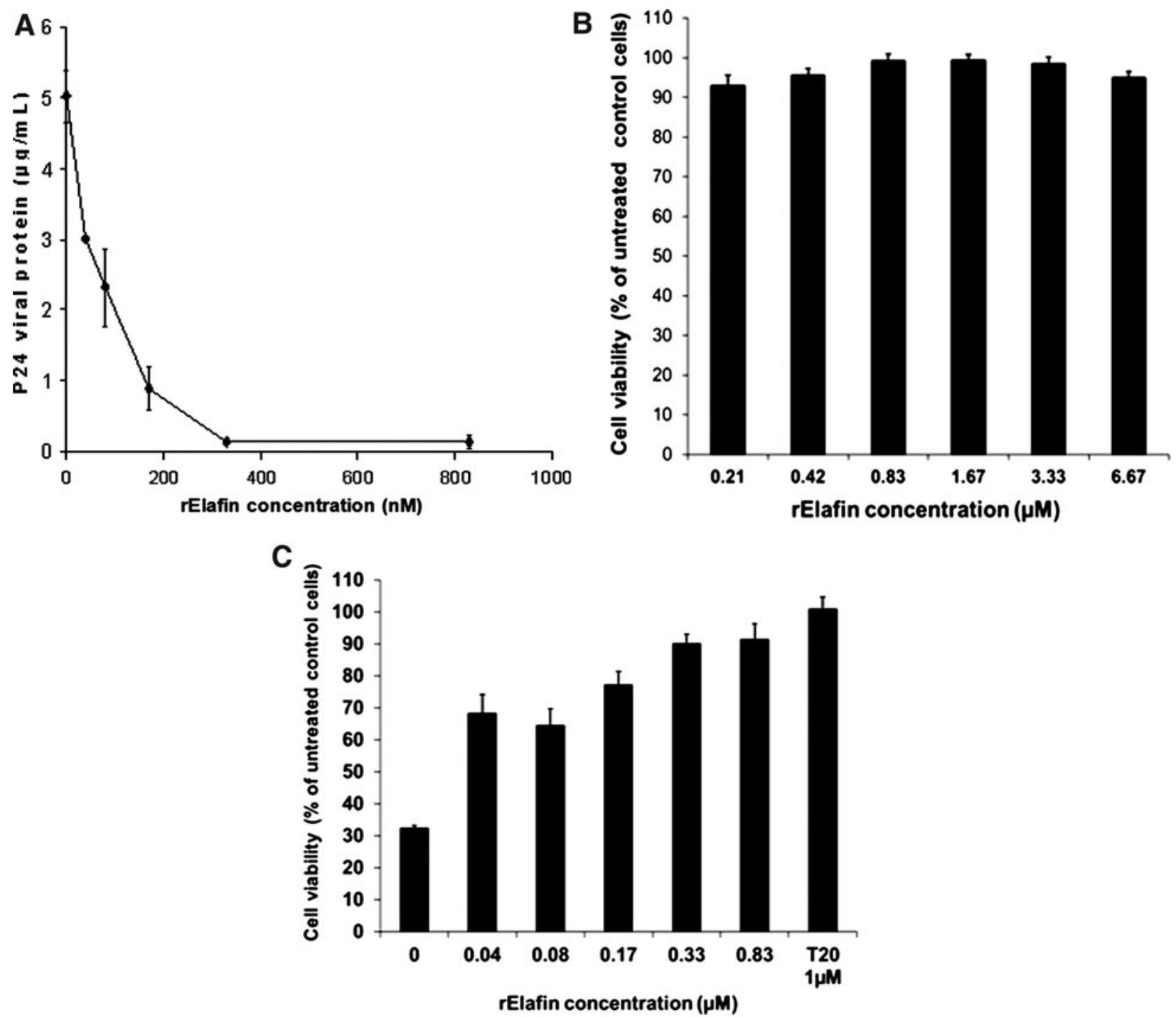

FIG. 2. Anti-HIV-1 IIIB activity of rElafin in T cells. HIV-1 IIIB virus was pre-incubated with rElafin or antiretroviral drugs for one hour prior to infection of Sup-T1 cells at MOI 0.1. After $2 \mathrm{~h}$, cells were rinsed with phosphate-buffered solution (PBS) and plated in a 96-well plate with fresh complete RPMI. At day 7, cell-free supernatants were collected to quantify viral p24 protein using an enzyme-linked immunosorbent assay (ELISA; A) and cells for cell viability evaluation by the MTT assay (C). Cytotoxicity assays were performed by exposing Sup-T1 cells at varying concentrations of rElafin (B). At day 4, cells were split and fresh culture medium containing rElafin was added. MTT assays were performed after 7 days of incubation (B). Values represent means \pm SEM. Values are expressed as \% of untreated control cells (negative control) in (B) and (C). Data are representative of three independent experiments $(n=3 ; \mathbf{A})$ or means of two independent experiments $(n=8 ; \mathbf{B}, \mathbf{C})$.

negative control cultures $(p<0.001)$. At higher doses, rElafin showed high potency to block HIV-1 cytolytic effect, reaching a plateau at $330 \mathrm{nM}$ with $90 \%$ protection compared to $32 \%$ in untreated/infected positive controls $(p<0.001)$. No significant difference was found between the protective effect of rElafin at 330 and $830 \mathrm{nM}$ and $1 \mu \mathrm{M}$ T20 $(p=0.054$ and 0.089 , respectively). The antiretroviral drug control T20, at $1 \mu \mathrm{M}$, completely protected the cells from cytopathic effect.

\section{Inhibition of HIV infection in PBMCs and THP-1 cells}

Next we evaluated the anti-HIV activity of rElafin in HIVinfected PBMCs and the monocyte/macrophage THP-1 cell line. Prior to HIV infection, PBMCs were first stimulated for $24 \mathrm{~h}$ with $1 \mu \mathrm{g} / \mathrm{mL}$ PHA-P and THP-1 cells treated with
$10 \mathrm{ng} / \mathrm{mL}$ PMA for 7 days, as described in Materials and Methods. HIV-1 IIIB (for PBMCs) or BaL (for THP-1) viruses were pre-incubated with rElafin for $1 \mathrm{~h}$ and then the cells were infected with their respective mixture. After $2 \mathrm{~h}$, the virus mixture was removed and fresh culture medium without drugs was added. Viral replication was quantified by measuring p24 protein production in supernatants after 7 days of infection. As in previous cells models, rElafin blocked HIV-1 replication in a concentration-dependent manner (Fig. 3). In PBMCs and THP-1 cells, rElafin showed potent anti-HIV activity with an $\mathrm{IC}_{50}$ of 176 and $89 \mathrm{nM}$, respectively (Table 1). In PBMCs, the p24 level was $2.10 \pm 1.33 \mathrm{ng} / \mathrm{mL}$ in uninfected and untreated negative control cells but was not detected in negative controls in the THP-1 cell model. Because rElafin showed similar antiHIV activity in PBMCs as in the established cell line Sup-T1, 


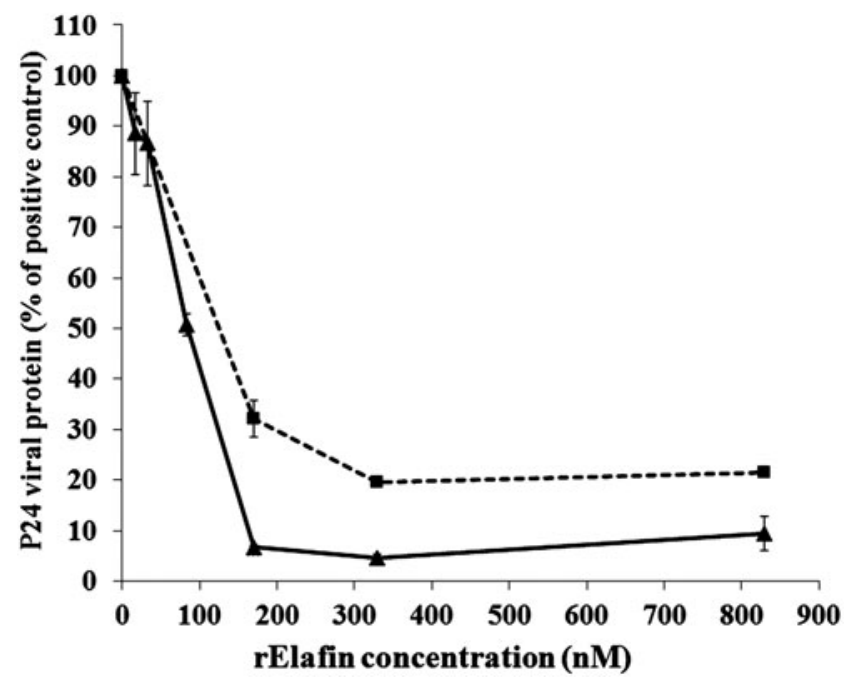

FIG. 3. Anti-HIV-1 activity of rElafin in peripheral blood mononuclear cells (PBMCs) and THP-1 cells. Prior to HIV-1 infection assays, PBMCs were stimulated with $1 \mu \mathrm{g} / \mathrm{mL}$ PHA-P for $24 \mathrm{~h}$ and THP-1 cells treated with $10 \mathrm{ng} / \mathrm{mL}$ phorbol 12-myristate 13-acetate (PMA) and allowed to differentiate into macrophages for 7 days. Cells were infected with a mixture of HIV-1 IIIB (-- $\square$--PBMC) or HIV-1 BaL (- $\mathbf{\Delta}-\mathrm{THP}-1)$ pre-incubated with rElafin for $1 \mathrm{~h}$, at a MOI of 0.1 . After $2 \mathrm{~h}$ of infection, cells were rinsed and cultured in complete culture medium without further addition of rElafin. After 7 days, supernatants were collected and p24 level measured by ELISA. Values represent means \pm SEM $(n=4)$ of HIVinfected but not rElafin treated control cells (positive control). Data are representative of two independent experiments.

the Sup-T1 T cells were used for the next series of experiments to study the mechanism of action of rElafin.

\section{Binding to host receptors or viral glycoproteins}

Further experiments were performed to better understand the anti-HIV mechanism of rElafin. The first steps of the infection cycle of HIV-1 include binding of viral gp120 glycoprotein to its primary cell surface receptor CD4 and key co-receptors, CXCR4 or CCR5, for X4- and R5-tropism virus, respectively. The interactions between gp120 and cellular receptors trigger a series of conformational transitions in gp41 that ultimately lead to the fusion of viral and cellular membrane allowing virus entry into target cells. Entry of HIV-1 can therefore be blocked by interference with either the viral glycoproteins or host elements such as CD4 and co-receptors CXCR4 or CCR5.

To determine whether rElafin blocks HIV-1 at the entry steps, experiments were first conducted to investigate the possible inhibitory activity of rElafin on the binding of viral envelope to CD4 receptor and CXCR4 co-receptor. First we looked for the ability of rElafin to directly bind to the viral envelope then to CD4 and CXCR4 receptors using two different cellular models: HeLa-env-Lai cells expressing gp120 and gp41 at their surface and CD4+/CXCR4 + Sup-T1 cells, respectively. Data with Sup-T1 cells are shown in Figure 4. Cells were incubated with rElafin at $330 \mathrm{nM}$ for $1 \mathrm{~h}$ and then rinsed and stained with anti-elafin, anti-CD4, or antiCXCR4 antibodies. Then cells were analyzed by flow cytom-
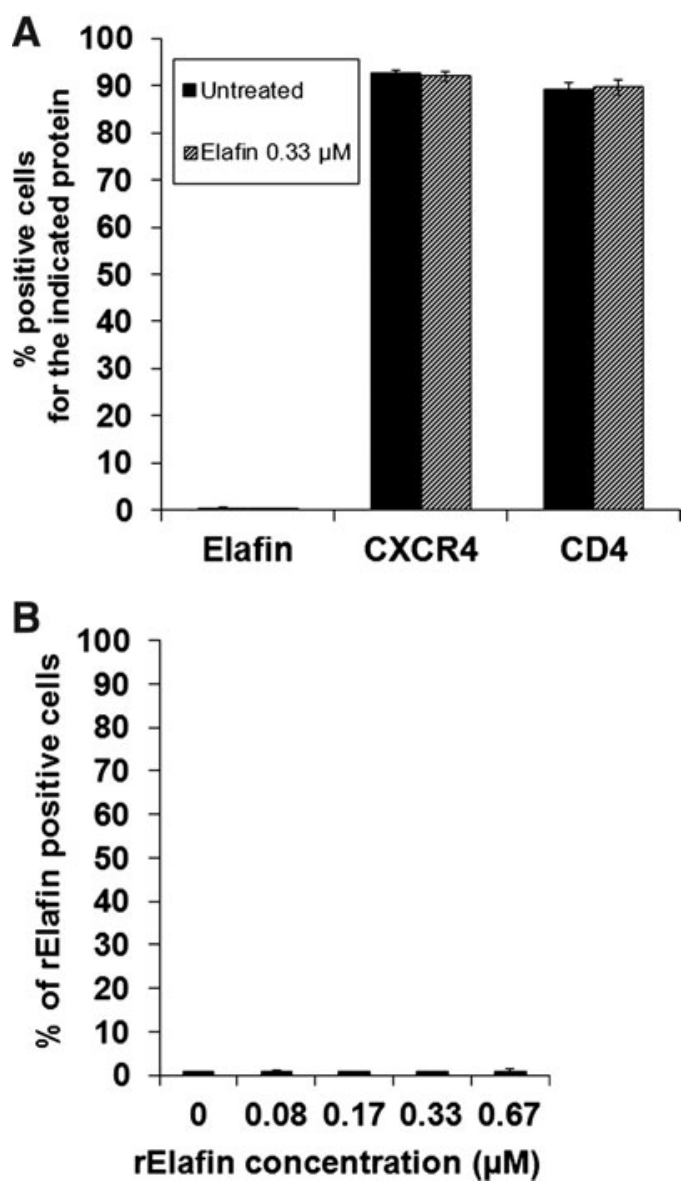

FIG. 4. Binding of rElafin to cell surface proteins. Sup-T1 cells or HeLa-env-Lai were incubated with $330 \mathrm{nM}$ or various concentrations of rElafin, respectively, for $1 \mathrm{~h}$ and then rinsed and stained with the rat anti-human Trappin-2/Elafin monoclonal antibody or with anti-human CD4 or CXCR4 antibodies. Bound rElafin, CD4, and CXCR4 were detected by flow cytometry. Values represent means \pm SEM of percentage of positive cells for the indicated protein on $x$-axis, after deduction of nonspecific background fluorescence of control IgG of two independent experiments done in duplicate $(n=4)$. No significant difference was found between cells exposed to rElafin and untreated control cells $(p<0.001)$.

etry for the presence of rElafin bound at their surface. No signal corresponding to FITC-anti-elafin antibody could be found neither at the surface of Sup-T1 cells (Fig. 4A) nor at the surface of HeLa-env-Lai cells (Fig. 4B) indicating that rElafin does not bind to CD4 or CXCR4 receptors and viral glycoproteins, respectively. High levels of CD4 and CXCR4 were found at the surface of rElafin-treated cells as in untreated control cells, showing that rElafin does not perturb the distribution or expression of these proteins (Fig. 4A). Moreover, in Western blot analysis using recombinant Elafin, CD4, and gp120 proteins, rElafin was not found bound to either CD4 or gp120 when incubated together (Supplementary Fig. S1).

\section{Effect on the expression of viral receptors at the surface of cells}

To further confirm that rElafin does not interact with host cell receptors, we tested its effect on the expression of CD4 


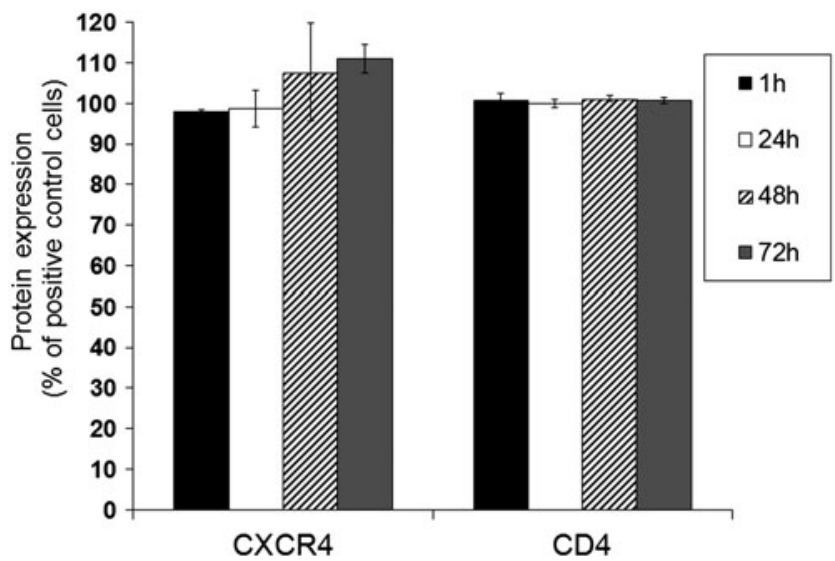

FIG. 5. Effect of rElafin on CXCR4 and CD4 protein expression on the surface of Sup-T1 cells. Cells were incubated with $330 \mathrm{nM}$ of rElafin for $1 \mathrm{~h}$ up to $72 \mathrm{~h}$ and then rinsed and stained with anti-human CXCR4 or CD4 antibody. Level of expression of CXCR4 and CD4 proteins was detected by flow cytometry. Data are expressed in terms of percentage of expression of cell surface markers compared to untreated control cells set at $100 \%$ after deduction of nonspecific background fluorescence of control IgG. Values represent means \pm SEM of at least two independent experiments done in duplicate $(n=4)$. No significant difference in the level of CD4 or CXCR4 expression on the surface of cells exposed to rElafin and untreated control cells at any time point $(p<0.001)$

and CXCR4 proteins on the surface of Sup-T1, up to $72 \mathrm{~h}$ using flow cytometry analysis. As in the previous assay, no effect on the expression of both CD4 and CXCR4 proteins could be observed following incubation of Sup-T1 cells up to $72 \mathrm{~h}$ (Fig. 5) or TZM-bl cells (data not shown) with
$330 \mathrm{nM}$ of rElafin. Under these same conditions, as expected, AZT did not affect CD4 and CXCR4 expression on the surface of Sup-T1 or TZM-bl cells (data not shown).

\section{Blockage of cell-to-cell fusion}

Next we investigated the ability of rElafin to interfere with membrane fusion using a cell-to-cell fusion assay. For this cell fusion experiment we used HeLa-env-Lai cells that stably express HIV-Lai glycoproteins gp120 and gp41 and the HIV-1 transactivator Tat, and TZM-bl cells that stably express the human CD4, CXCR4, and CCR5 receptors and $\beta$-gal and luciferase under the control of HIV LTR. In this assay, if fusion occurs between the cells, Tat will be transferred into the cytosol of TZM-bl, resulting in transactivation of the LTR, initiation of the transcription of lac $Z$ gene, and then production of $\beta$-galactosidase in the cells. We found that, in contrast to $1 \mu \mathrm{M}$ T20 which significantly inhibited cell fusion, rElafin at $1 \mu \mathrm{M}$ and AZT at $10 \mu \mathrm{M}$ did not block cell fusion when compared to untreated/HIV-infected positive controls (Fig. 6A). Both formation of giant cells (Fig. 6A) and $\beta$-galactosidase activity (Fig. 6B) were similar in cells treated with either rElafin or AZT but significantly lower in cells treated with T20 when compared to control cultures.

\section{Discussion}

Previous studies have reported the anti-HIV-1 activity of trappin-2/elafin, ${ }^{19-21}$ but to date there is still controversy about its role as an innate immune factor to protect from HIV-1 transmission and infection in vivo, and its anti-HIV mechanism of action is still not yet understood. ${ }^{21,27}$ The main goal of this study was to further confirm the antiHIV-1 activity of elafin by comparing its antiviral activity
A

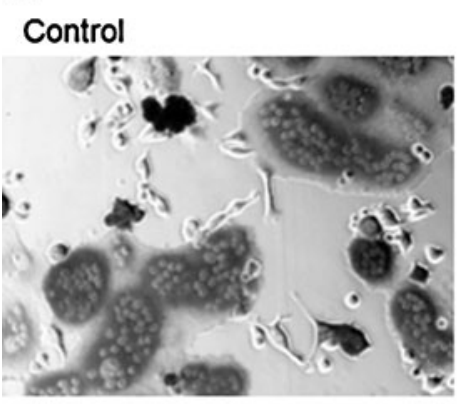

AZT $10 \mu \mathrm{M}$

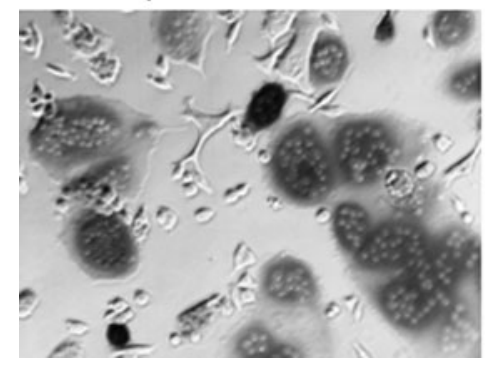

rElafin $1 \mu \mathrm{M}$

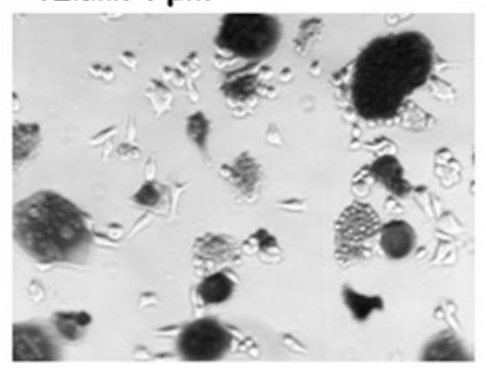

$\mathrm{T} 201 \mu \mathrm{M}$

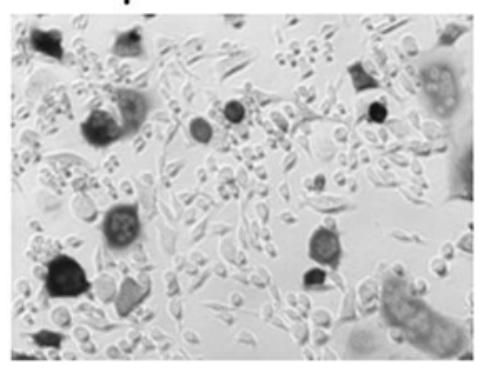

B

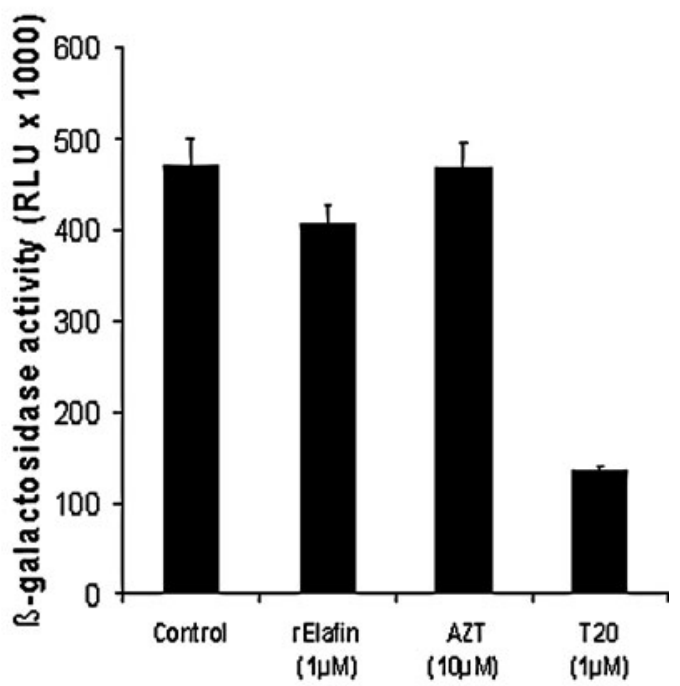

FIG. 6. Cell-to-cell fusion assay. HeLa-env-Lai cells were incubated with rElafin or antiretroviral drugs for $1 \mathrm{~h}$ prior to the addition of TZM-bl cells. Control wells correspond to untreated HIV-1 infected cell cultures. After $24 \mathrm{~h}, \beta$-galactosidase activity was analyzed by Zeiss epifluorescence microscopy (A) or quantified by the Beta-Glo assay (B). Data are representative of three independent experiments. Values represent means $\pm \operatorname{SEM}(n=4) .{ }^{* *}$ Significantly lower than untreated controls, $p<0.001$. 
with antiretroviral drugs in natural host target cells and to better understand its mechanism. Inhibitory effect of human rElafin on X4-tropic HIV-1 IIIB strain replication was first determined by measuring the virus-induced $\beta$ galactosidase activity in infected TZM-bl genital epithelial cells. In this assay, we found that rElafin more potently inhibited viral replication when pre-incubated with the virus prior to infection than when added to the cells $2 \mathrm{~h}$ after infection. These data suggest that rElafin interferes with the early steps of HIV-1 infection. Our findings are in agreement with previous studies showing in vitro antiviral activity of recombinant trappin-2/elafin in the TZM-bl indicator cell line. ${ }^{20,21}$ Ghosh et al. ${ }^{20}$ reported that rTrappin-2/ elafin is more potent when it interacts with the virus prior to infecting the cells than when added to the cells after infection, as we also found. However, they reported a lower $\mathrm{IC}_{50}$ $(\sim 2 \mathrm{nM})$, than the one found here and in Drannick et al. ${ }^{21} \mathrm{~A}$ partial explanation for this discrepancy might reside in the experimental design, which differed between studies. Here we have quantified viral replication $24 \mathrm{~h}$ post-infection instead of $48 \mathrm{~h}$ as in the previous study. ${ }^{20}$ We chose to measure viral infection after $24 \mathrm{~h}$ to eliminate possible cumulative inhibitory effects from a second round of infection as observed in TZM-bl cells in a period longer than $24 \mathrm{~h}$ post-infection (data not shown). Therefore, it might be possible that in the previous study, ${ }^{20}$ the authors achieved a high level of inhibition using lower doses of trappin-2/elafin because their methodology design was different (cell density, viral dose, time of incubation, etc.). But most likely, this might indicate that the precursor protein trappin-2 contains important structures in its cementoin domain, which is absent in elafin, that might enhance its antiviral activity by interacting with either the virus or other host cell molecules to further block HIV infection. Experiments are ongoing to further investigate this hypothesis.

To further confirm the anti-HIV activity of elafin and investigate its mechanism, we used the Sup-T1 T-cell line, the THP-1 monocyte/macrophage cell line, and human PBMCs, all natural target immune cells for HIV. TZM-bl cells are epithelial HeLa engineered cells expressing canonical HIV-1 receptor components, CD4, CXCR4, and CCR5, that allow them to be infected by HIV-1. In this cell model, viral replication is monitored by reporter assays. Infection of T cells, macrophages, and PBMCs with HIV-1 are cell models that more closely correlate with in vivo HIV-1 infection of target immune cells, thus better allowing investigation of the potential of elafin as an antiviral agent. We found that in both Sup-T1 T cells and primary PBMCs, rElafin was more potent in blocking HIV-1 IIIB than in TZM-bl cells (9- and 4-fold, respectively) and in blocking HIV-BaL in THP-1 macrophages (8-fold). In addition, the slopes of the inhibition curves were steeper in these cell models than in the genital epithelial cell model TZM-bl, indicating higher potency in immune target cells than in HeLaengineered cells. Furthermore, rElafin protected $\mathrm{T}$ cells from the cytopathic effects of the virus up to $70 \%$ using physiological doses such as $250 \mathrm{ng} / \mathrm{mL}(40 \mathrm{nM})$, possibly by interfering with the new virions and preventing them from infecting cells de novo. We had previously determined that under physiologically conditions, the concentration of trappin-2/elafin was around $100 \mathrm{ng} / \mathrm{mL}$ and elevated to $280 \mathrm{ng} / \mathrm{mL}$ in CVL of HIV-resistant women. ${ }^{22-23}$ Although previous studies have shown in vitro anti-HIV activity in HeLa-engineered TZM-bl cells, ${ }^{20,21}$ our study is the first to demonstrate viral inhibition in target $\mathrm{T}$ cells, macrophages, and primary cells. Therefore, altogether, our findings suggest that at physiological concentrations, trappin-2/elafin might play a role in the protection from HIV infection.

Data from the present study and other studies suggest that trappin-2/elafin acts at early steps in the replication cycle of the virus. HIV-1 entry is initiated by the binding of viral gp120 glycoprotein to cell surface receptor CD4 molecule and a co-receptor (CXCR4/CCR5). Many molecules have been reported to have potent in vitro activity against HIV replication by interfering with HIV cellular entry. ${ }^{12,28}$ It has been demonstrated that the anti-HIV mechanism of the secretory leucocyte proteinase inhibitor (SLPI), a wellcharacterized serine protease inhibitor in the same family as trappin-2/elafin, does not result from a direct interaction with the virus but is rather due to an interaction with the cellular membrane of the host cells. ${ }^{29-31}$ SLPI binds to the phospholipid-binding protein annexin II, disrupting the interaction of the human cell-derived phosphatidylserine of the HIV-1 envelope with annexin II. ${ }^{32}$ Recently, it was shown that SLPI is a ligand for the phospholipid scramblase 1 (PLSCR1) and PSLCR4, and that SLPI might inhibit HIV-1 infection of T cells by modulating the interaction of the CD4 receptor with PLSCRs. ${ }^{32}$ Therefore we hypothesized that elafin, which is closely related to SLPI, might also interact with host cell surface proteins involved in HIV-1 binding and entry. However, in this study we clearly demonstrated that pre-incubation of $\mathrm{T}$ cells and HeLa-derived TZM-bl cells expressing CD4, CXCR4, and CCR5 proteins with rElafin, does not influence the level of expression of CD4 and coreceptor CXCR4 at the surface of TZM-bl and Sup-T1 cell membrane. These data are in agreement with the previous findings showing that in TZM-bl and HEC-1A cells, trappin-2 and elafin do not alter cellular expression of CXCR4 and syndecan-1 (CD38), an alternative binding molecule for HIV-1 attachment to HEC-1A cells. ${ }^{21}$ In addition, here we showed that rElafin does not bind to CD4, co-receptor CXCR4, or any other molecules at the surface of the TZM-bl genital epithelial or T-cell membrane, indicating that elafin does not act by interfering or masking HIV-1 receptors on these cells. Moreover, the possibility of binding to viral glycoproteins was also investigated in this study using different assays. Our results from the cell-to-cell fusion assays indicate that the inhibitory activity of rElafin does not have an impact on the binding of gp120 to HIV-1 receptors or interfere with gp41 for fusion with the cell membrane. In addition, we found that rElafin does not bind directly to gp120 or to gp41 since no rElafin was found at the surface of HeLa-env-Lai cells, which express both viral glycoproteins, following $1 \mathrm{~h}$ of preincubation. Moreover, in our cell-to-cell fusion assays, we confirmed that rElafin did not bind to CD4, CXCR4, or CCR5 proteins expressed at the surface of TZM-bl cells, which would have blocked the fusion between TZM-bl and HeLa-env-Lai cells. Furthermore, preliminary results using Western blot analysis confirmed this lack of binding between rElafin and host or viral proteins. Altogether, our results from the cell-to-cell fusion assays, binding assays, and incubation assays indicate that the inhibitory activity of rElafin is not through a direct interaction with viral glycoproteins or HIV-1 receptors or due to an effect on the level of expression 
of host receptors. Because elafin is positively charged, it's unlikely that it bound to Env glycans as observed with polyanionic compounds such as dextran sulfate ${ }^{33,34}$ or with carbohydrate-binding proteins such as lectins. ${ }^{35}$ On the other hand, our study suggest that elafin also does not behave as the polycations aminoglycosides that block HIV cell entry by competing with gp120-CD4/CXCR4 interaction. ${ }^{36}$ Further investigation will be required to confirm the exact mechanism of the antiviral activity of elafin, but our findings and findings from other studies strongly suggest a possible role at the early steps of infection and possibly before integration of the viral DNA into the genome of the cell. Blocking HIV-1 before integration of proviral DNA into the host genome has clear advantages over blocking subsequent stages in the life cycle of the virus. Additional experiments to elucidate the anti-HIV mechanism of trappin-2/elafin are ongoing in our laboratory and further investigations using a broader panel of HIV viral strains including clinical isolates are required.

\section{Conclusions}

Taken together, the data of this study provide important additional information on anti-HIV activity of the innate immune factor trappin-2/elafin. We have shown that rElafin significantly inhibited X4-tropic HIV-1IIIB replication in engineered genital epithelial cells, target $\mathrm{T}$ cells and primary immune cells, and R5-tropic HIV-1 BaL in monocytes/macrophages without binding to host cell receptors CD4, CXCR4, or CCR5 or to viral capsid proteins gp41 and gp120. Our current data suggest that trappin-2/elafin interferes with the early steps of HIV replication with a different mechanism than enfuvirtide (T20). The ability of elafin to act at an early step in the viral replication cycle to block infection of both X4and R5-tropic virus strains in immune target cells as demonstrated in this study makes trappin-2/elafin a promising candidate for its development as an anti-HIV microbicide.

\section{Acknowledgments}

This work has been supported by the Public Health Agency of Canada. V.J.J. thanks the Natural Sciences and Engineering Research Council of Canada (NSERC) for his postdoctoral fellowship. We are grateful to Michèle Bergeron and Tao Ding for their technical help with the flow cytometry analysis. We thank Germaine Fortier for her technical assistance with the cell cultures.

\section{Author Disclosure Statement}

No competing financial interests exist.

\section{References}

1. Sallenave JM, Shulmann J, Crossley J, et al. Regulation of secretory leukocyte proteinase inhibitor (SLPI) and elastasespecific inhibitor (ESI/elafin) in human airway epithelial cells by cytokines and neutrophilic enzymes. Am J Respir Cell Mol Biol. 1994;11:733-741.

2. Simpson AJ, Wallace WA, Marsden ME, et al. Adenoviral augmentation of elafin protects the lung against acute injury mediated by activated neutrophils and bacterial infection. J Immunol. 2001;167:1778-1786.

3. Williams SE, Brown TI, Roghanian A, et al. SLPI and elafin: one glove, many fingers. Clin Sci (Lond). 2006;110:21-35.
4. Bingle CD, Vyakarnam A. Novel innate immune functions of the whey acidic protein family. Trends Immunol. 2008;29: 444-453.

5. Wilkinson TS, Roghanian A, Simpson AJ, et al. WAP domain proteins as modulators of mucosal immunity. Biochem Soc Trans. 2011;39:1409-1415.

6. Kato I, Tominaga N. Trypsin-subtilisin inhibitor from red sea turtle eggwhite consists of two tandem domains: one Kunitz, one of a new family. Fed Proc. 1979;38:832.

7. Pfundt R, van Ruissen F, van Vlijmen-Willems IM, et al. Constitutive and inducible expression of SKALP/elafin provides anti-elastase defense in human epithelia. J Clin Invest. 1996;98:1389-1399.

8. Bingle L, Tetley TD, Bingle CD. Cytokine-mediated induction of the human elafin gene in pulmonary epithelial cells is regulated by nuclear factor-kappaB. Am J Respir Cell Mol Biol. 2001;25:84-91.

9. Wiedow O, Schroder JM, Gregory H, et al. Elafin: an elastasespecific inhibitor of human skin. purification, characterization, and complete amino acid sequence. J Biol Chem. 1990; 265:14791-14795.

10. Schalkwijk J, Wiedow $\mathrm{O}$, Hirose S. The trappin gene family: proteins defined by an N-terminal transglutaminase substrate domain and a C-terminal four-disulphide core. Biochem J. 1999;340:569-577.

11. Pol A, Pfundt R, Zeeuwen $P$, et al. Transcriptional regulation of the elafin gene in human keratinocytes. J Invest Dermatol. 2003;120:301-307.

12. Moreau T, Baranger K, Dade $S$, et al. Multifaceted roles of human elafin and secretory leukocyte proteinase inhibitor (SLPI), two serine protease inhibitors of the chelonianin family. Biochimie. 2008;90:284-295.

13. Sallenave JM, Ryle AP. Purification and characterization of elastase-specific inhibitor. sequence homology with mucus proteinase inhibitor. Biol Chem Hoppe Seyler. 1991;372:13-21.

14. Wiedow $\mathrm{O}$, Luademann J, Utecht B. Elafin is a potent inhibitor of proteinase 3. Biochem Biophys Res Commun. 1991; 174:6-10.

15. Molhuizen HO, Alkemade HA, Zeeuwen PL, et al. SKALP/ elafin: an elastase inhibitor from cultured human keratinocytes. purification, cDNA sequence, and evidence for transglutaminase cross-linking. J Biol Chem. 1993;268: 12028-12032.

16. Simpson AJ, Maxwell AI, Govan JR, et al. Elafin (elastasespecific inhibitor) has anti-microbial activity against grampositive and gram-negative respiratory pathogens. FEBS Lett. 1999;452:309-313.

17. McMichael JW, Maxwell AI, Hayashi K, et al. Antimicrobial activity of murine lung cells against Staphylococcus aureus is increased in vitro and in vivo after elafin gene transfer. Infect Immun. 2005;73:3609-3617.

18. Baranger K, Zani ML, Chandenier J, et al. The antibacterial and antifungal properties of trappin-2 (pre-elafin) do not depend on its protease inhibitory function. FEBS J. 2008;275:2008-2020.

19. Ball TB, Iqbal SM, Plummer, FAinventors; ADE \& Company Inc., assignee. Trappin-2 (elafin) inhibits HIV. United States Patent US 20,090,163,409 A1. 2009 Jun 25.

20. Ghosh M, Shen Z, Fahey JV, et al. Trappin-2/Elafin: a novel innate anti-human immunodeficiency virus-1 molecule of the human female reproductive tract. Immunology. 2010;129: 207-219.

21. Drannik AG, Nag K, Yao XD, et al. Anti-HIV-1 activity of elafin is more potent than its precursor's, trappin-2, in genital epithelial cells. J Virol. 2012;86:4599-4610. 
22. Iqbal SM, Ball TB, Levinson $P$, et al. Elevated elafin/trappin-2 in the female genital tract is associated with protection against HIV acquisition. AIDS. 2009;23:1669-1677.

23. Burgener A, Rahman S, Ahmad R, et al. Comprehensive proteomic study identifies serpin and cystatin antiproteases as novel correlates of HIV-1 resistance in the cervicovaginal mucosa of female sex workers. J Proteome Res. 2011;10:5139_ 5149.

24. Ghosh M, Fahey JV, Shen Z, et al. Anti-HIV activity in cervical-vaginal secretions from HIV-positive and -negative women correlate with innate antimicrobial levels and IgG antibodies. PloS One. 2010b;5:e11366.

25. Derdeyn CA, Decker JM, Sfakianos JN, et al. Sensitivity of human immunodeficiency virus type 1 to the fusion inhibitor $\mathrm{T}-20$ is modulated by coreceptor specificity defined by the V3 loop of gp120. J Virol. 2000;74:8358-8367.

26. Kappes JC, Wu X, inventors; UAB Research Foundation, assignee. Cell-based method and assay for measuring the infectivity and drug sensitivity of immuno-deficiency virus. United States Patent US 6,797,4622 B1. 2004 Sep 28.

27. Ellegard R, Shankar EM, Larsson M. Targeting HIV-1 innate immune responses therapeutically. Curr Opin HIV AIDS. 2011;6:435-443.

28. Lederman MM, Jump R, Pilch-Cooper HA, et al. Topical application of entry inhibitors as "virustats" to prevent sexual transmission of HIV infection. Retrovirology. 2008;5:116.

29. McNeely TB, Shugars DC, Rosendahl M, et al. Inhibition of human immunodeficiency virus type 1 infectivity by secretory leukocyte protease inhibitor occurs prior to viral reverse transcription. Blood. 1997;90:1141-1149.

30. Tseng CC, Tseng CP. Identification of a novel secretory leukocyte protease inhibitor-binding protein involved in membrane phospholipid movement. FEBS Lett. 2000;475: 232-236.
31. Ma G, Greenwell-Wild T, Lei K, et al. Secretory leukocyte protease inhibitor binds to annexin II, a cofactor for macrophage HIV-1 infection. J Exp Med. 2004;200: 1337-1346.

32. Py B, Basmaciogullari S, Bouchet J, et al. The phospholipid scramblases 1 and 4 are cellular receptors for the secretory leukocyte protease inhibitor and interact with CD4 at the plasma membrane. PloS One. 2009;4:e5006.

33. Leydet A, Barthelemy P, Boyer B, et al. Polyanion inhibitors of human immunodeficiency virus and other viruses. 1. polymerized anionic surfactants. J Med Chem. 1995;38: 2433-2440.

34. Cabrera C, Gutierrez A, Blanco J, et al. Anti-human immunodeficiency virus activity of novel aminoglycoside-arginine conjugates at early stages of infection. AIDS Res Hum Retroviruses. 2000;16:627-634.

35. Balzarini J. Large-molecular-weight carbohydrate-binding agents as HIV entry inhibitors targeting glycoprotein gp120. Curr Opin HIV AIDS. 2006;1:355-360.

36. Lapidot A, Berchanski A, Borkow G. Insight into the mechanisms of aminoglycoside derivatives interaction with HIV-1 entry steps and viral gene transcription. FEBS J. 2008;275:5236-5257.

Address correspondence to: Carole Lavigne, PhD National HIV and Retrovirology Laboratories National Microbiology Laboratory Public Health Agency of Canada 200 Tunney's Pasture Driveway Ottawa, ON K1A 0K9

Canada

E-mail: carole.lavigne@phac-aspc.gc.ca 